\title{
Cytoplasmic PPARy is a marker of poor prognosis in patients with Cox-1 negative primary breast cancers
}

Wanting Shao ${ }^{1}$, Christina Kuhn ${ }^{1}$, Doris Mayr ${ }^{2}$, Nina Ditsch, Magdalena Kailuwait ${ }^{1}$, Verena Wolf ${ }^{1}$, Nadia Harbeck', Sven Mahner', Udo Jeschke ${ }^{1 *} \mathbb{B}$, Vincent Cavaillès ${ }^{3}$ and Sophie Sixou ${ }^{1,4,5}$

\begin{abstract}
Background: The aim of this study was to investigate the expression of the nuclear receptor PPARY, together with that of the cyclooxygenases Cox-1 and Cox-2, in breast cancer (BC) tissues and to correlate the data with several clinicobiological parameters including patient survival.

Methods: In a well characterized cohort of 308 primary BC, PPARy, Cox-1 and Cox-2 cytoplasmic and nuclear expression were evaluated by immunohistochemistry. Correlations with clinicopathological and aggressiveness features were analyzed, as well as survival using Kaplan-Meier analysis.

Results: PPARy was expressed in almost $58 \%$ of the samples with a predominant cytoplasmic location. Cox- 1 and Cox-2 were exclusively cytoplasmic. Cytoplasmic PPARY was inversely correlated with nuclear PPARY and ER expression, but positively with Cox-1, Cox-2, and other high-risk markers of BC, e.g. HER2, CD133, and N-cadherin. Overall survival analysis demonstrated that cytoplasmic PPARy had a strong correlation with poor survival in the whole cohort, and even stronger in the subgroup of patients with no Cox-1 expression where cytoplasmic PPARy expression appeared as an independent marker of poor prognosis. In support of this cross-talk between PPARY and Cox-1, we found that Cox-1 became a marker of good prognosis only when cytoplasmic PPAR y was expressed at high levels.

Conclusion: Altogether, these data suggest that the relative expression of cytoplasmic PPARY and Cox-1 may play an important role in oncogenesis and could be defined as a potential prognosis marker to identify specific high risk BC subgroups.
\end{abstract}

Keywords: PPARy, Cytoplasmic, Cox-1, Cox-2, Overall survival, Breast cancer

\section{Background}

Breast cancer $(\mathrm{BC})$, the most commonly diagnosed malignant tumor in women, is also the most frequent cause of cancer death worldwide [1] and a significant global public health problem. BC is highly heterogeneous in its pathological characteristics, which raised a tremendous challenge for treatment selection [2].

*Correspondence: udo.jeschke@med.uni-muenchen.de

${ }^{1}$ Breast Center, Department of Obstetrics and Gynecology, University Hospital, LMU Munich, Munich, Germany

Full list of author information is available at the end of the article
So far, few biomarkers have been well recognized in invasive breast carcinomas, including estrogen receptor (ER) and progesterone receptor (PR), which are associated with a better outcome and are predictive of endocrine sensitivity. Overexpression of human epidermal growth factor receptor 2 (HER2) is related with decreased relapse-free survival (RFS) and overall survival (OS) [3, 4]. Agents targeting ER and HER2, such as tamoxifen and trastuzumab, have been very successful as $\mathrm{BC}$ therapeutics. However, multifaceted mechanisms emerged in tumors, causing resistance to endocrine treatment in single or combination therapies [5]. Thus,

(c) The Author(s) 2020. This article is licensed under a Creative Commons Attribution 4.0 International License, which permits use, sharing, adaptation, distribution and reproduction in any medium or format, as long as you give appropriate credit to the original author(s) and the source, provide a link to the Creative Commons licence, and indicate if changes were made. The images or other third party material in this article are included in the article's Creative Commons licence, unless indicated otherwise in a credit line to the material. If material is not included in the article's Creative Commons licence and your intended use is not permitted by statutory regulation or exceeds the permitted use, you will need to obtain permission directly from the copyright holder. To view a copy of this licence, visit http://creativecommons.org/licenses/by/4.0/. The Creative Commons Public Domain Dedication waiver (http://creativecommons.org/publicdomain/zero/1.0/) applies to the data made available in this article, unless otherwise stated in a credit line to the data. 
comprehensive identification of more biomarkers and molecular targets is essential for optimal and personalized clinical BC management.

Peroxisome proliferator-activated receptors (PPARs) belong to the nuclear receptor (NR) superfamily [6] and function as ligand-activated transcription factors [7]. Following activation by ligands (e.g. $15 \mathrm{~d}-\mathrm{PGJ}_{2}$ or the synthetic ligand thiazolidinedione), PPARs heterodimerize with retinoid X receptor (RXR) and interact with proliferator-activated receptor response elements (PPREs) present in target gene promoters [8]. Although the NR superfamily was defined due to genomic actions of the receptors which require nuclear localization, it has been suggested that PPARs localize first in the cytoplasm with specific associated functions [9].

Among the three PPAR isoforms $(\alpha, \beta / \delta$ and $\gamma)$, PPAR $\gamma$ plays a crucial role in adipogenesis and lipid metabolism [10] and is also found expressed in many human cancers, including BC [11]. PPAR $\gamma$ influences inflammatory processes, cell proliferation, differentiation, apoptosis and tumor angiogenesis $[10,12]$. A tumor promoting effect of PPAR $\gamma$ has been reported in some tumors, such as liver [13], cancer [14] or colon cancer [15]. In addition, most of previous studies have revealed that PPAR $\gamma$ acts as a tumor suppressor in $\mathrm{BC}$, inhibiting cell proliferation and inducing apoptosis in different in vivo and in vitro models [16-18]. Besides, PPAR $\gamma$ has been suggested as being involved in chemotherapy resistance of TNBC [19].

Interestingly, some of the PPAR ligands, prostaglandins (PGs) are produced from the conversion of arachidonic acid by the cyclooxygenases Cox- 1 and Cox- 2 . Cox-1 is constitutively expressed in many normal cells, whereas Cox-2 is generally considered being induced by inflammatory cytokines and growth factors, performing a significant role in carcinogenesis [20,21]. Studies of Cox importance in tumor progression and invasion were mainly focused on the influence of Cox-2 [22]. However, it was demonstrated that Cox-1 is highly expressed and plays a pivotal role in some carcinomas, such as ovarian [23] and breast cancers [24]. More recently, Cox-1 mRNA and protein levels have been shown to be higher in malignant breast tumors than in normal tissues, whereas Cox-2 mRNA level was lower in malignant tumors. Nonetheless, stromal and glandular Cox-2 immunostaining showed higher levels in malignant breast tumors [25].

It appears therefore obvious that more attention is needed to analyze the relevance of combined expression of PPAR $y$ and Cox (especially Cox-1) in BC. In the present study, we have analyzed expression of PPARy and of the two Cox proteins in 308 primary $\mathrm{BC}$ specimens in relation to survival, to determine if either one could, independently or in relation to the others, be linked to $\mathrm{BC}$ progression.

\section{Methods}

\section{Patient cohort}

A total of 308 formalin-fixed paraffin-embedded primary BC tissues from 303 patients ( 5 of them are bilateral BC) who received surgeries between 2000 and 2002 at the Department of Obstetrics and Gynecology of the Ludwig-Maximilians-University Munich, Germany were collected. Local and systemic therapy treatment was given according to the guidelines at the time of diagnosis. This study was approved by the Ethical Committee of the Medical Faculty, Ludwig-Maximilian-University, Munich, Germany (approval number 048-08) and informed consent for nuclear factor analysis was obtained from all patients who were alive at the time of follow-up. Data, such as age, histological grade, metastases, local recurrence, progression, and survival were retrieved from the Munich Cancer Registry and anonymized and encoded during statistical analysis and experiments. All tumors were assessed according to UICC TNM classification, containing tumor size and extent of tumors (primary tumor size, or pT, classified as: pT1a-c, pT2, pT3, pT4ad), lymph node status $(\mathrm{N})$, and presence or absence of metastasis (M). Tumor grade was determined by an experienced pathologist (Dr. D. Mayr) of the Department of Pathology of the LMU, according to a modification of Elston and Ellis grading proposed by Bloom and Richardson [26]. Sixty (19.48\%) of the 303 primary BC patients, became metastatic during the follow-up. ER, PR, HER2, Ki-67 and histological status were all determined by an experienced pathologist of the LMU Department of Pathology, as described below. HER2 2+ scores were further evaluated through fluorescence in situ hybridization (FISH) testing.

\section{Immunohistochemistry (IHC)}

Expression of ER $\alpha, P R$, and HER2 was determined at diagnosis in all BC samples of this cohort at the LMU Department of Pathology, Germany. ER $\alpha$ and PR expression were evaluated by immunohistochemistry, as described previously [26]. Samples showing nuclear staining in more than $10 \%$ of tumor cells were considered as hormone receptor-positive, in agreement with the guidelines at the time of the analysis (2000-2002). HER2 expression was analyzed using an automated staining system (Ventana; Roche, Mannheim, Germany), according to the manufacturer's instructions. Ki-67 was stained using an anti-Ki67 monoclonal antibody (Dako, Hamburg, Germany) at a dilution of 1:150 on a VENTANA ${ }^{\circledR}$-Benchmark Unit (Roche, Mannheim, Germany) as previously described [27]. The Ki-67 cut-off used to differentiate luminal A from luminal B tumors (all HER2 negative) was $14 \%$ as this was commonly used at the time of the analysis, although $20 \%$ is now preferred 
[28]. Data on N-cadherin and CD133 expression in these $\mathrm{BC}$ samples were extracted from a previously published study [29]. For PPAR $\gamma$, Cox-1 and Cox-2 analysis by IHC, samples were processed as previously described [30,31]. Briefly, sections were first cut and prepared from paraffin-embedded BC samples using standard protocols. Phosphate buffered saline (PBS) was used for all washes and sections were incubated in blocking solution (ZytoChem Plus HRP Polymer System Kit, ZYTOMED Systems $\mathrm{GmbH}$, Berlin, Germany) before incubation with primary antibodies. All primary antibodies were rabbit IgG polyclonal used at a $1: 100$ dilution for $16 \mathrm{~h}$ at $4{ }^{\circ} \mathrm{C}$ : anti-PPARY (ab59256, Abcam, Cambridge, UK) or antiCox-1 (HPA002834) and anti-Cox-2 (SAB4502491, both Sigma-Aldrich, Saint Louis, MO, USA). After incubation with a biotinylated secondary anti-rabbit IgG antibody, and with the associated avidin-biotin-peroxidase-complex (both Vectastain Elite ABC Kit; Vector Laboratories, Burlingame, CA, USA), visualization was performed with substrate and chromogen 3,3-diamino-benzidine (DAB; Dako, Glostrup, Denmark). Negative and positive controls were used to assess the specificity of the immunoreactions. Negative controls (colored in blue) were performed in $\mathrm{BC}$ tissue by replacement of the primary antibodies by species-specific (rabbit) isotype control antibodies (Dako, Glostrup, Denmark). Appropriate positive controls (placenta samples) were included in each experiment. Sections were counterstained with acidic hematoxylin, dehydrated and immediately mounted with Eukitt (Merck, Darmstadt, Germany) before manual analysis with a Diaplan light microscope (Leitz, Wetzlar, Germany) with $25 \times$ magnification. Pictures were obtained with a digital CCD camera system (JVC, Tokyo, Japan). All slides were analyzed by two or three independent examiners.

\section{Immunoreactive score (IRS)}

The expression of PPAR $\gamma$, Cox-1 and Cox-2 was assessed according to the immunoreactive score (IRS), determined by evaluating the proportion of positive tumor cells, scored as 0 (no staining), 1 ( $\leq 10 \%$ of stained cells), 2 (11-50\% of stained cells), 3 (51-80\% of stained cells) and 4 ( $\geq 80 \%$ of stained cells), and the intensity of their staining, graded as 0 (negative), 1 (weak), 2 (moderate) and 3 (strong) (IRS $=$ percentage score $\times$ intensity score). Thus, the range of IRS value is from 0 to 12 . As previously described for LCoR and RIP140 [31] and for AhR [32], PPAR $\gamma$ cytoplasmic and nuclear staining were evaluated in parallel, with a separate determination of cytoplasmic IRS and nuclear IRS. Total IRS was calculated by addition of cytoplasmic and nuclear IRS. For all other markers, staining and IRS were determined in the whole cells, without differentiation of nuclear and cytoplasmic staining.

\section{Survival and statistical analysis}

Receiver operating characteristic curve (ROC) analyses were performed to calculate the optimal cut-off values between low and high PPAR $\gamma$, Cox- 1 and Cox- 2 expressions, based upon the maximal differences of sensitivity and specificity. The threshold determined regarding OS were an IRS $\geq 3.5$ for either total or cytoplasmic PPAR $\gamma$, $\geq 0.5$ for nuclear PPARy and for Cox-1, and finally $\geq 1.5$ for Cox-2. These thresholds were used to determine the percentages of tumors expressing low or high PPAR , Cox-1 and Cox-2 levels described in Table 2, besides the OS analysis detailed below. To present the mean immunoreactivity levels described by the IRS in Table 2, the groups were divided into low- vs. high-expressing cases for total and cytoplasmic PPAR $\gamma$, Cox-2, or into not expressing vs. expressing cases for nuclear PPAR $\gamma$, Cox-1 (cut-off values of 0.5).

Differences in nuclear PPAR $y$ expression among three or more groups (Fig. 1, panel k) were tested using the non-parametric Kruskal-Wallis rank-sum test. Correlation analyses presented in Tables 3 and 4 were performed by calculating the Spearman's-Rho correlation coefficient ( $\mathrm{p}$ values of Spearman's-Rho test presented). Survival times were compared by Kaplan-Meier graphics and differences in OS (or RFS) were tested for significance by using the Chi-square statistics of the log rank test. Data were assumed to be statistically significant in the case of p-value $<0.05$. Kaplan-Meier curves and estimates were then provided for each subgroup and each marker. The $p$ value and the number of patients analyzed in each subgroup are given for each chart.

Multivariable analysis for outcome (OS) presented in Table 5 was performed using the Cox regression model, and included cytoplasmic PPAR $\gamma$ expression and relevant clinicopathological characteristics as independent variables. Variables were selected based on theoretical considerations and forced into the model. $p$ values and hazard ratios were indicated, knowing that the hazard ratios of covariates are interpretable as multiplicative effects on the hazard, and holding the other covariates constant.

Statistical analyses were performed using SPSS 24 (IBMSPSS Statistics, IBM Corp., Armonk, NY, USA). For all analyses, p values below $\left.0.05{ }^{(*)}\right), 0.01{ }^{(* *)}$, or 0.001 $(* * *))$ were considered statistically significant.

\section{Results}

PPARy and Cox expression in breast cancers

The total cohort consisted of 308 samples from 303 primary BC (Table 1). Median age of initial diagnosis was 57.98 years (range 26.66-94.62 years) and median 


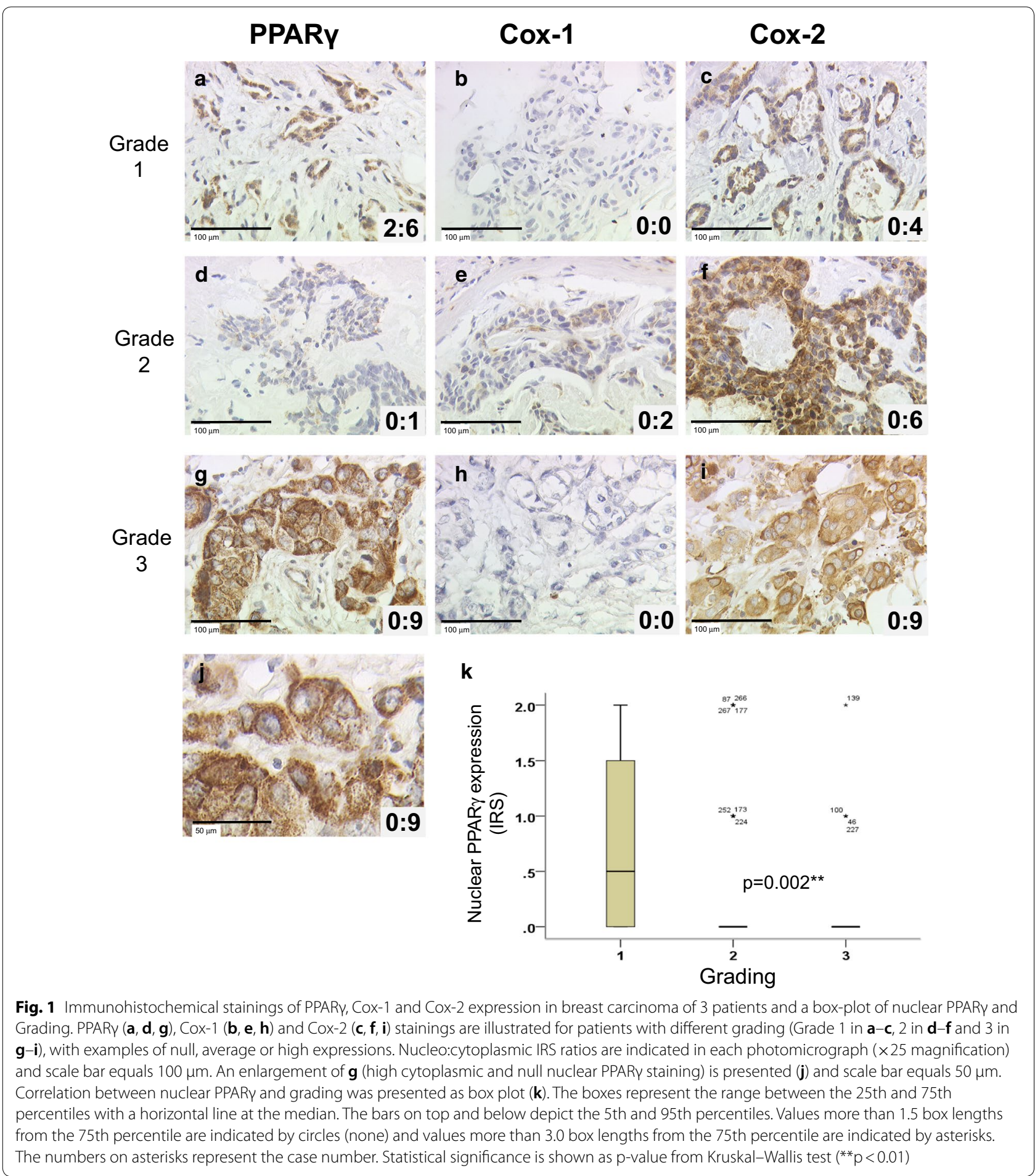

follow-up time was 125 months (range 0-153 months). During this period, 41 (13.3\%) and 60 (19.5\%) cases experienced local recurrence and distant metastasis respectively, and 90 (29.2\%) women died.
The expression of PPAR $\gamma$, Cox-1 and Cox-2 was analyzed by IHC staining, as illustrated in Fig. 1 for 3 patients with Grade 1 (A, B, C), 2 (D, E, F) and $3(\mathrm{G}, \mathrm{H}$, I) tumors. PPAR $\gamma$ expression $(A, D, G)$ was present both 
Table 1 Clinical and pathological characteristics of all patients

\begin{tabular}{|c|c|c|}
\hline $\begin{array}{l}\text { Clinical and pathological } \\
\text { characteristics }^{\mathrm{a}}\end{array}$ & $N=308^{b}$ & $\%$ \\
\hline Age, median (years) & 57.98 & \\
\hline Follow up, average (months) & 109.89 & \\
\hline Median & 125 & \\
\hline \multicolumn{3}{|l|}{ Histology ${ }^{c}$} \\
\hline Invasive lobular & 41 & 13.31 \\
\hline Invasive medullar & 10 & 3.25 \\
\hline Invasive mucinous & 3 & 0.97 \\
\hline No special type (NST) & 161 & 52.27 \\
\hline DCIS with NST & 78 & 25.33 \\
\hline Unknown & 15 & 4.87 \\
\hline \multicolumn{3}{|l|}{ ER status } \\
\hline Positive & 248 & 80.52 \\
\hline Negative & 58 & 18.83 \\
\hline Unknown & 2 & 0.65 \\
\hline \multicolumn{3}{|l|}{ PR status } \\
\hline Positive & 178 & 57.79 \\
\hline Negative & 128 & 41.56 \\
\hline Unknown & 2 & 0.65 \\
\hline \multicolumn{3}{|l|}{ HER2 status } \\
\hline Positive & 35 & 11.36 \\
\hline Negative & 271 & 87.99 \\
\hline Unknown & 2 & 0.65 \\
\hline \multicolumn{3}{|l|}{ Molecular subtype } \\
\hline Luminal A (Ki-67 $\leq 14 \%)$ & 170 & 55.19 \\
\hline Luminal B (Ki-67 > 14\%) & 63 & 20.45 \\
\hline HER2 positive luminal & 27 & 8.77 \\
\hline HER2 positive non luminal & 8 & 2.60 \\
\hline Triple negative & 38 & 12.34 \\
\hline Unknown & 2 & 0.65 \\
\hline \multicolumn{3}{|l|}{ Grade } \\
\hline । & 15 & 4.87 \\
\hline$\|$ & 102 & 33.12 \\
\hline III & 45 & 14.61 \\
\hline Unknown & 146 & 47.40 \\
\hline \multicolumn{3}{|l|}{ Tumor size } \\
\hline pT1 & 191 & 62.01 \\
\hline pT2 & 87 & 28.25 \\
\hline pT3 & 4 & 1.30 \\
\hline pT4 & 12 & 3.90 \\
\hline Unknown & 14 & 4.55 \\
\hline \multicolumn{3}{|l|}{ Lymph node metastasis } \\
\hline Yes & 126 & 40.91 \\
\hline No & 163 & 52.92 \\
\hline Unknown & 19 & 6.17 \\
\hline \multicolumn{3}{|l|}{ Local recurrence $^{d}$} \\
\hline Yes & 41 & 13.31 \\
\hline No & 253 & 82.14 \\
\hline Unknown & 14 & 4.55 \\
\hline
\end{tabular}

Table 1 (continued)

\begin{tabular}{llr}
\hline $\begin{array}{l}\text { Clinical and pathological } \\
\text { characteristics }\end{array}$ & $\mathbf{N}=\mathbf{3 0 8}^{\mathbf{b}}$ & $\%$ \\
\hline $\begin{array}{l}\text { Distant metastases } \\
\text { e }\end{array}$ & 60 & 19.48 \\
Yes & 234 & 75.97 \\
No & 14 & 4.55 \\
\hline Unknown & \\
\hline a All information given refer to the primary tumor & \\
b 5 of 303 patients are bilateral primary BC, so we deal with the tumor as \\
individual one ( $\mathrm{n}=308$ ) \\
" NST include the formerly called "Invasive ductal" and "other" types \\
d Local recurrence has been detected during the follow-up of 40 patients (1 of \\
them are bilateral BC, so $\mathrm{n}=41$ ) \\
e Distant metastasis has been detected during the follow-up of 58 patients (2 of \\
them are bilateral BC, so $\mathrm{n}=60$ )
\end{tabular}

in the nucleus and in the cytoplasm, while Cox-1 and Cox-2 (B, E, H, and C, F, I respectively) were exclusively cytoplasmic. The nucleo:cytoplasmic IRS ratios are presented in each panel (panel J shows the enlargement of PPAR $\gamma$ staining shown in panel G). From now, all Cox-1 and Cox-2 expression refers to their unique cytoplasmic expression, with Cox-1 staining being much fainter than Cox-2 staining, as described in Table 2. As demonstrated in the panel $\mathrm{K}$, nuclear PPARy exhibited a statistically different expression according to grading, with an inverted correlation $(\mathrm{p}=0.002)$. This correlation is illustrated by focusing on the nuclear PPAR $\gamma$ expression observed in panels A, D and G of Fig. 1 (IRS of 2, 0 and 0 respectively) for patients with respectively grade 1,2 and 3 tumors.

As presented in Table 2, the mean IRS of total and cytoplasmic PPARy expression were 4.37 and 4.09 respectively, while it was 0.27 for nuclear PPAR $\gamma$. It clearly appears that, in our cohort, PPARy expression is dramatically higher (15-fold) in the cytoplasm than in the nucleus, with maximal IRS values of 12 and 4 respectively. This is exemplified in Fig. 1 with cytoplasmic PPAR $\gamma$ IRS values of 1, 6 and 9, and nuclear PPAR IRS values of 0 and 2 (panels A, D and J). IRS cut-offs were defined by performing a ROC-curve analysis for OS. Of note, the IRS cut-off of 0.5 generated for nuclear PPARY staining is related to the low expression level of this marker in our cohort, and create sub-groups with negative vs. positive expression, instead of low vs. high expression for other cut-off values. Considering cytoplasmic or total expression of PPAR $\gamma$ being high for IRS value $>3.5$, the high expression group is predominant in both cases (52.7 and $57.6 \%$ respectively). Only 20 patients out of 262 (7.6\%) had no cytoplasmic PPARy expression (IRS $=0$ ), demonstrating the predominant cytoplasmic expression of PPARY (92.4\% of the tumors). 
Table 2 Distribution of expression of PPARy, Cox-1 and Cox-2

\begin{tabular}{|c|c|c|c|c|c|}
\hline & \multicolumn{3}{|l|}{ PPARY } & \multirow[t]{2}{*}{ Cox-1 } & \multirow[t]{2}{*}{ Cox-2 } \\
\hline & Total & Nuclear & Cytoplasmic & & \\
\hline$n$ & 262 & 262 & 262 & 297 & 285 \\
\hline Mean IRS \pm SE & $4.37 \pm 0.17$ & $0.27 \pm 0.04$ & $4.09 \pm 0.17$ & $0.34 \pm 0.04$ & $5.19 \pm 0.19$ \\
\hline IRS range & 12 & 4 & 12 & 4 & 12 \\
\hline IRS cut-off & 3.5 & 0.5 & 3.5 & 0.5 & 1.5 \\
\hline $\begin{array}{l}\text { Number of samples with } \\
\text { negative/low expression }\end{array}$ & 111 (42.4\%) & $213(81.3 \%)$ & 124 (47.3\%) & 224 (75.4\%) & $36(12.6 \%)$ \\
\hline $\begin{array}{l}\text { Number of samples with } \\
\text { positive/high expression }\end{array}$ & 151 (57.6\%) & $49(18.7 \%)$ & 138 (52.7\%) & $73(24.6 \%)$ & $249(87.4 \%)$ \\
\hline
\end{tabular}

IRS cut-offs were defined by performing a ROC-curve analysis for DFS. The cut-off of 0.5 for nuclear PPARy and for Cox- 1 stainings, related to the low expression level of both markers in our cohort, define negative and positive expressions, instead of low and high expressions sub-groups respectively

Table 3 Correlation between PPARy, Cox-1 and Cox-2 expression

\begin{tabular}{lllll}
\hline $\mathrm{n}=254$ to 297 & PPARy & & Cox-1 Cox-2 \\
\cline { 2 - 4 } & Total Nuclear $\quad$ Cytoplasmic & & \\
& & &
\end{tabular}

\section{PPARY}

\begin{tabular}{llllll} 
Total & 1.000 & & & & \\
Nuclear & 0.037 & 1.000 & & & \\
Cytoplasmic & $0.959^{* *}$ & $-0.215^{* *}$ & 1.000 & & \\
Cox-1 & $0.179^{* *}$ & -0.117 & $0.201^{* *}$ & 1.000 & \\
Cox-2 & $0.261^{* *}$ & $-0.124^{*}$ & $0.293^{* *}$ & 0.054 & 1.000 \\
\hline
\end{tabular}

Correlations are statistically significant for $p<0.05(*)$ or $p<0.01(* *)$, using Spearman-Rho-Test

Besides, the mean IRS of cytoplasmic expression were 0.34 and 5.19 for Cox-1 and Cox-2 respectively. This is again exemplified in Fig. 1 with Cox-1 IRS values of 0 and
2 (panels B, E and H) and Cox-2 IRS values of 4, 6 and 9 (panels $\mathrm{C}, \mathrm{F}$ and I), for the same 3 selected patients. Similarly to nuclear PPAR $\gamma$, Cox-1 mean IRS being very low, a cut-off of 0.5 was generated, with sub-groups of negative vs. positive expression, instead of low vs. high expression for Cox-2. In our cohort, $75.4 \%$ of the samples were then Cox-1 negative, whereas the samples with a high expression of Cox-2 represented $87.37 \%$ of the cases (cut-off of 1.5). Regarding nuclear PPAR $\gamma$, only 49 samples were positive (18.7\%) while for Cox-1, only 73 samples (24.6\%) were positive (with maximum IRS of 4 for both markers).

\section{Correlation between PPARY and Cox expression}

The correlations between the expression levels of PPAR $\gamma$ (total, nuclear and cytoplasmic), Cox-1 and Cox-2 were analyzed (Table 3). Cytoplasmic PPAR $\gamma$ expression exhibited a strong and significant positive correlation with total PPAR $\gamma$, and a negative one with nuclear PPARy. By

Table 4 Correlation between PPARy, Cox-1 and Cox-2 expression and clinicopathological or aggressiveness related parameters

\begin{tabular}{|c|c|c|c|c|c|}
\hline & \multicolumn{3}{|c|}{ PPAR $y=143$ to 262} & \multirow{2}{*}{$\begin{array}{l}\text { Cox-1 } \\
n=159 \text { to } 297\end{array}$} & \multirow{2}{*}{$\begin{array}{l}\text { Cox-2 } \\
n=153 \text { to } 285\end{array}$} \\
\hline & Total & Nuclear & Cytoplasmic & & \\
\hline Age & 0.004 & -0.050 & 0.002 & 0.041 & -0.015 \\
\hline pT & 0.118 & -0.037 & 0.113 & -0.049 & -0.066 \\
\hline $\mathrm{pN}$ & 0.069 & 0.023 & 0.065 & $-0.125^{*}$ & -0.043 \\
\hline Grade & 0.007 & $-0.205^{*}$ & 0.054 & -0.007 & -0.062 \\
\hline ER & -0.119 & 0.117 & $-0.142^{*}$ & 0.009 & 0.039 \\
\hline$P R$ & -0.048 & 0.038 & -0.049 & -0.018 & 0.012 \\
\hline HER2 & $0.157^{* *}$ & $-0.127^{*}$ & $0.173^{* *}$ & $0.137^{*}$ & 0.090 \\
\hline Triple negative & 0.076 & -0.062 & 0.085 & -0.043 & -0.052 \\
\hline Ki-67 & 0.116 & -0.039 & 0.119 & 0.084 & $0.155^{*}$ \\
\hline Focality & 0.043 & 0.074 & 0.016 & -0.048 & -0.028 \\
\hline CD133 & $0.221^{* *}$ & -0.007 & $0.230^{* *}$ & $0.132^{*}$ & $0.378^{* *}$ \\
\hline NCAD & $0.412^{* *}$ & $-0.196^{* *}$ & $0.447^{* *}$ & $0.241^{* *}$ & $0.461^{* *}$ \\
\hline
\end{tabular}

Correlations are statistically significant for $p<0.05\left({ }^{*}\right)$ or $p<0.01(* *)$, using Spearman-Rho-Test 
contrast, nuclear and total expression of PPAR $\gamma$ were not correlated together. Regarding Cox expression, Cox-1 and Cox-2 levels were not correlated. Nonetheless, both Cox-1 and Cox-2 expression were significantly correlated with cytoplasmic and total PPAR $\gamma$ expressions. Besides, nuclear PPAR $\gamma$ was significantly negatively correlated with Cox-2 (and not with Cox-1).

\section{Correlation between PPARy, Cox expression and clinicopathological parameters or aggressiveness markers}

We then analyzed the correlations between PPAR $\gamma$ or Cox expression and known clinicopathological characteristics (Table 4). We also quantified the expression of two aggressiveness markers, CD133, a widely used marker for isolating cancer stem cell (CSC) [33, 34], and N-cadherin, a well-known marker for epithelial-tomesenchymal transition (EMT) [35]. Considering first nuclear PPAR $\gamma$, significant negative correlations were observed with grade (as already illustrated in Fig. 1k, and by the 3 selected patients in Fig. 1), HER2 and N-cadherin, as well as Cox-2 (as already shown in Table 3). On the contrary, total and cytoplasmic PPAR $\gamma$ were strongly positively correlated with HER2, CD133 and N-cadherin. Only cytoplasmic PPAR $\gamma$ was negatively correlated to ER. Besides, Cox-1 was positively correlated with HER2, CD133, and N-cadherin, while Cox-2 was positively correlated with $\mathrm{Ki}-67, \mathrm{CD} 133$, and N-cadherin. Only Cox-1 was statistically negatively correlated with lymph node status (LNM), and only Cox-2 was positively correlated with the proliferation marker Ki-67.

\section{Correlation between PPAR $y$, Cox expression, and patient survival}

In order to analyze the correlation between PPAR $\gamma$ and survival, we performed Kaplan-Meier analyses. We used the cut-off IRS values determined by ROC-curve analysis, allowing the maximal difference of sensitivity and specificity (as described in Table 2). In Fig. 2, considering the OS of the whole cohort, the cytoplasmic PPAR $\gamma$ expression was able to discriminate high expressing tumors with a significantly worse survival than patients with low expressing tumors (mean OS: 10.55 years vs 9.44 years, $\mathrm{p}=0.027$; Fig. 2a). On the contrary, neither nuclear PPAR $\gamma$ (Fig. 2b) nor total PPAR $\gamma$ (Additional file 1: Figure S1A) had any significant correlation with OS.

RFS analysis were performed in parallel for total, cytoplasmic and nuclear PPARy expression (Additional file 1: Figure S1B-D respectively). Both total and cytoplasmic PPAR $\gamma$ significantly discriminated patients with worse RFS (when PPARy was highly expressed) from those having better survival when PPAR $\gamma$ expression was low (mean RFS: 9.37 years vs 6.88 years, $\mathrm{p}=0.001$, and mean RFS: 9.30 years vs 6.70 years, $\mathrm{p}=0.000217$ ).

We then looked at the association between cytoplasmic PPAR $\gamma$ expression and OS in different subgroups by stratifying the cohort, according to parameters mentioned in Table 4. Compared to the correlation of cytoplasmic PPARy expression with OS in the whole cohort $(\mathrm{p}=0.027$, Fig. 2a), the correlation was stronger in the subgroup of luminal A tumors ( $p=0.005$ Fig. $2 c)$, and lost in the luminal B subgroup (Fig. 2d). Similarly, the correlation was very strong in the subgroup of N-Cadherin low expressing tumors $(\mathrm{p}=0.007$, Fig. $2 \mathrm{e})$ and absent in the $\mathrm{N}$-Cadherin high expressing tumors (Fig. 2f).

We then focused on subgroups of patients according to Cox expression in their tumors. As demonstrated in Fig. 3, expression of cytoplasmic PPAR $\gamma$ was still clearly related to a worse prognosis in the subgroup of tumors expressing no Cox $-1(\mathrm{p}=0.001$, Fig. 3a), as observed in the whole cohort $(p=0.027$, Fig. $2 a)$. On the contrary, no correlation of cytoplasmic PPAR $\gamma$ existed with the OS of patients with tumor expressing Cox-1, and the trend, although not significant, was even inverted with an apparently better prognosis for group with high cytoplasmic PPAR $\gamma$ expression (Fig. 3b).

In the subgroup of patients with low Cox-2 expression (using a cut-off IRS of 7), expression of cytoplasmic PPAR $\gamma$ was still related to a poor prognosis $(\mathrm{p}=0.009$, Fig. 3c) while no correlation of cytoplasmic PPAR $\gamma$ and OS existed for the patients with high Cox-2 expression (Fig. 3d).

\section{Cytoplasmic PPARy expression as an independent prognostic parameter of OS in $\mathrm{N}$-cadherin low and Cox-1 negative tumors}

We then performed multivariate analyses for the whole cohort and for the subgroups of patients described above, using the Cox regression model with cytoplasmic PPAR $\gamma$ expression and various clinicopathological features (age at time of diagnosis, tumor size, ER, and HER2 status). As shown in Table 5, data demonstrated that in the whole cohort, only age, tumor size and ER were independent prognostic markers of OS. Very interestingly, cytoplasmic PPARy appeared as an independent prognosis marker in the $\mathrm{N}$-cadherin low (IRS $<3.5)$ and Cox-1 negative subgroups $(\mathrm{p}=0.044$ and $\mathrm{p}=0.014$ respectively), with hazard ratios of 1.996 and 2.047 indicating a much higher risk of death for the patients with tumors expressing high levels of cytoplasmic PPAR $\gamma$.

On the opposite, cytoplasmic PPAR $\gamma$ had no independent prognostic value in the $\mathrm{N}$-cadherin high or Cox-1 positive expressing subgroups, in the subgroups with low or high Cox-2 expression (IRS cut-off of 7) or even in the Luminal A subgroup (data not shown). The same analysis 

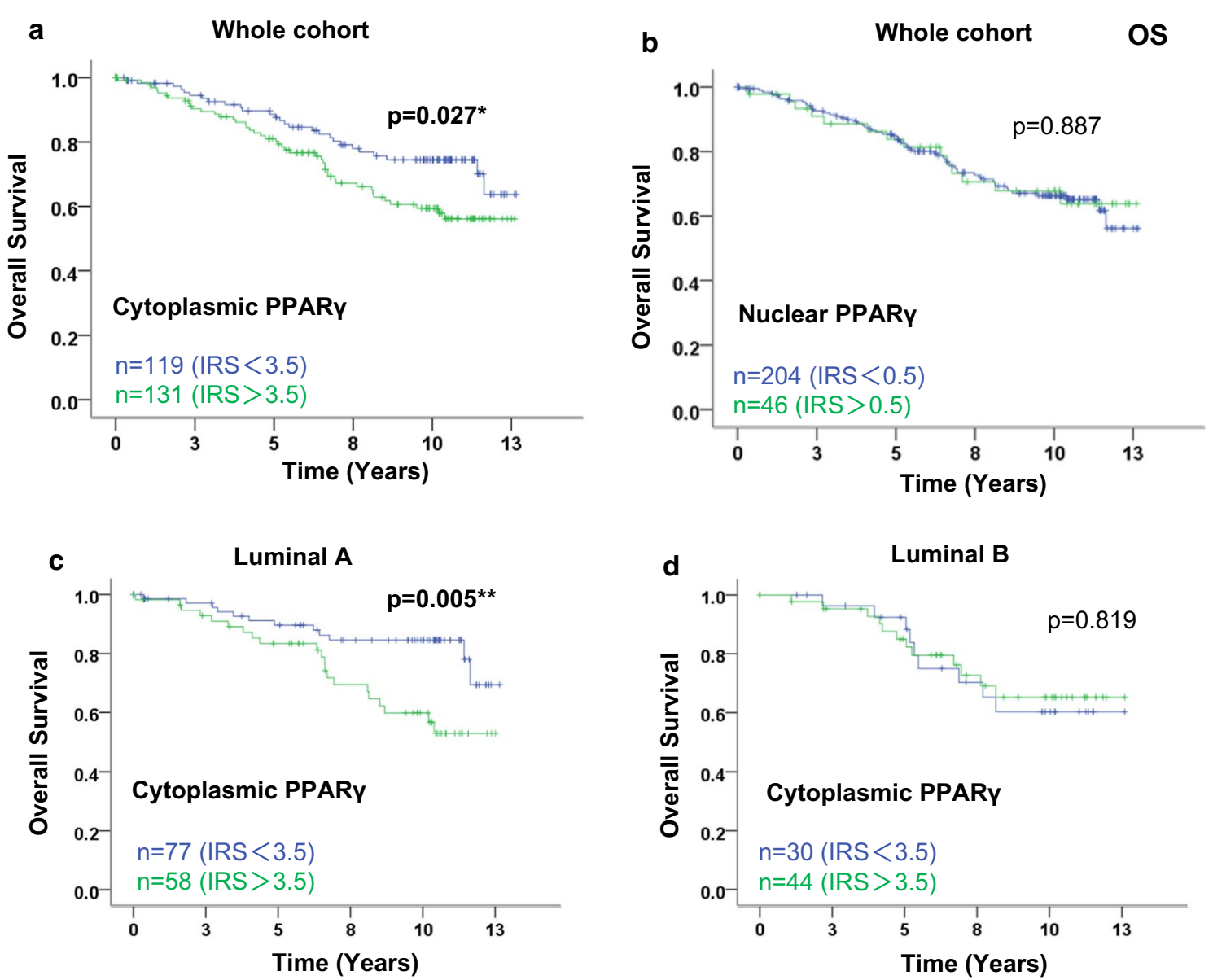

e $\quad \mathrm{N}$-Cadherin low expression (IRS $<3.5)$
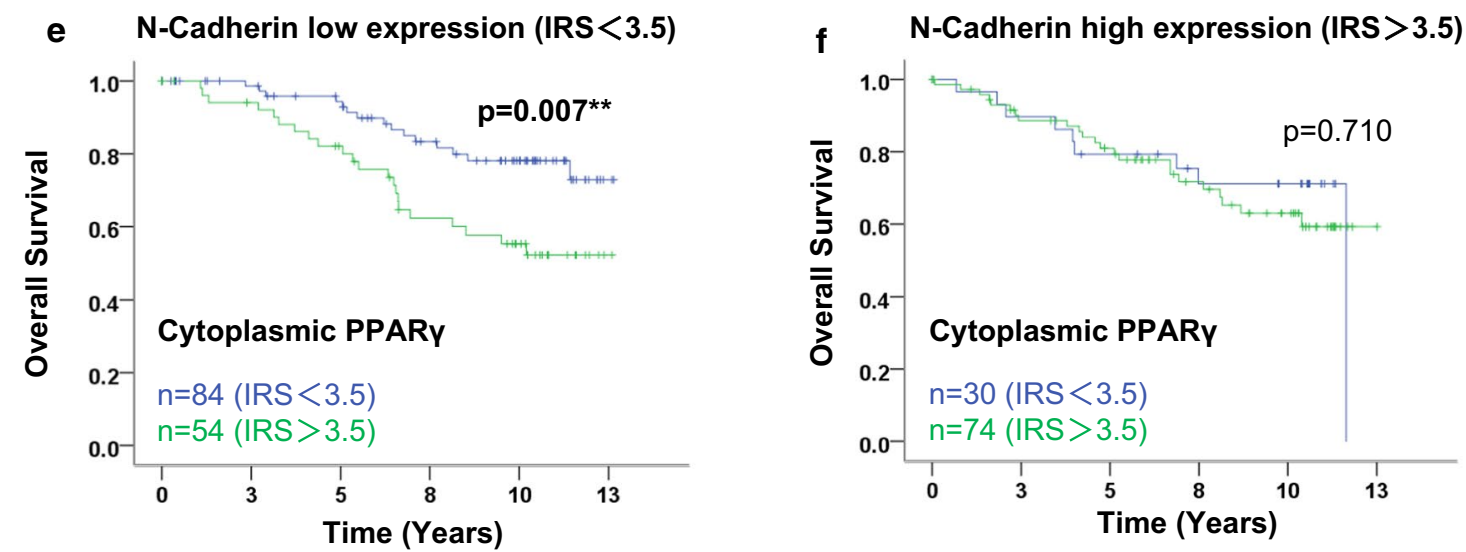

Fig. 2 Kaplan-Meier analysis of patient overall survival according to nuclear and cytoplasmic PPARy expression in the whole cohort, and to cytoplasmic PPARY expression in subgroups. In the whole cohort, overall survival (OS) curves are presented according to cytoplasmic PPARY (a) and nuclear PPARY (b) status. In luminal (c, d) and N-Cadherin (e, f) subgroups, overall survival curves are presented according to cytoplasmic PPARY status. The IRS cut-off values with the number of cases for each group are indicated in each graph. Statistical significance is shown as $p$-value from log-rank test $\left({ }^{*} p<0.05 ;{ }^{* *} p<0.01\right)$ 

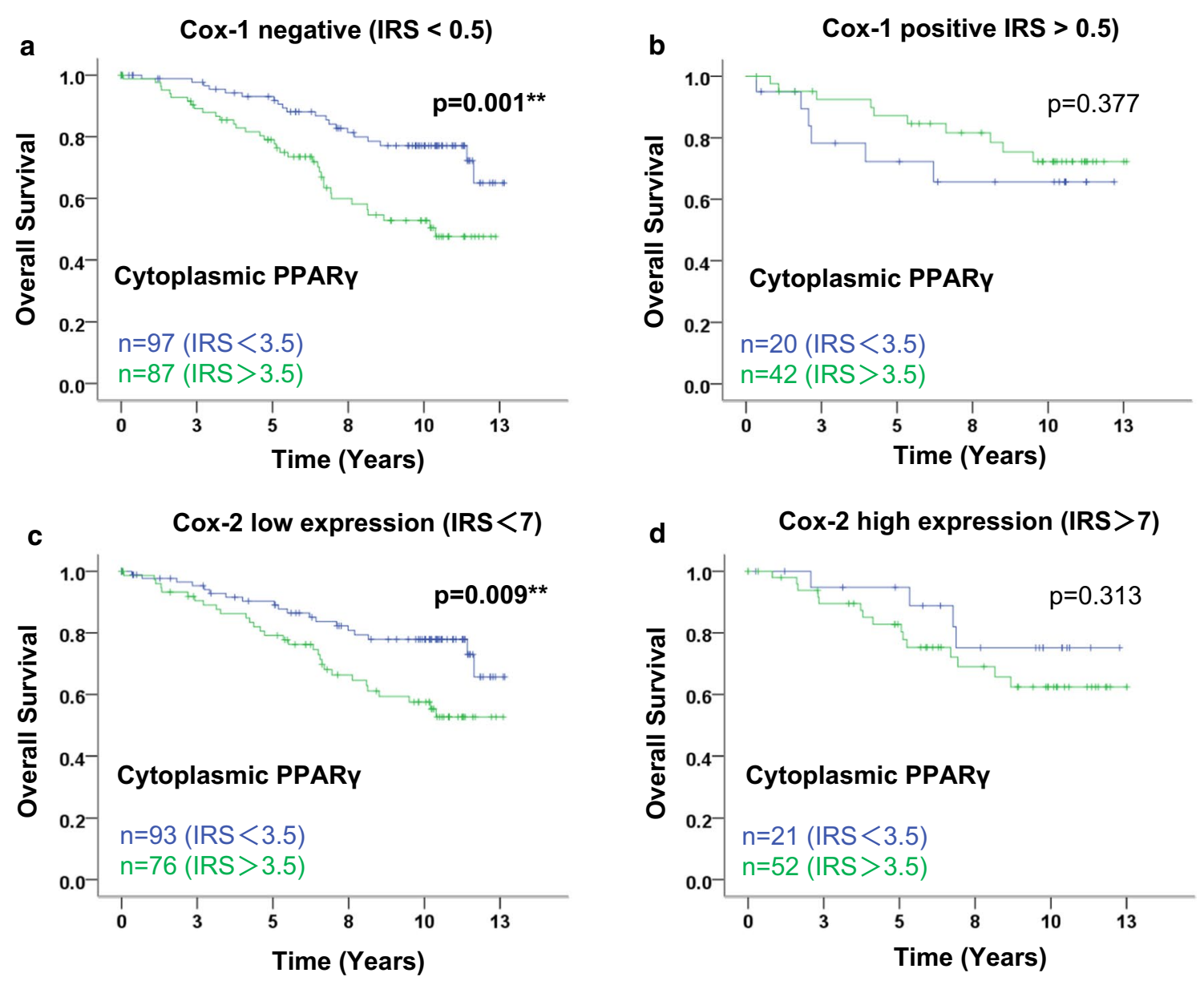

Cytoplasmic PPAR $\gamma$
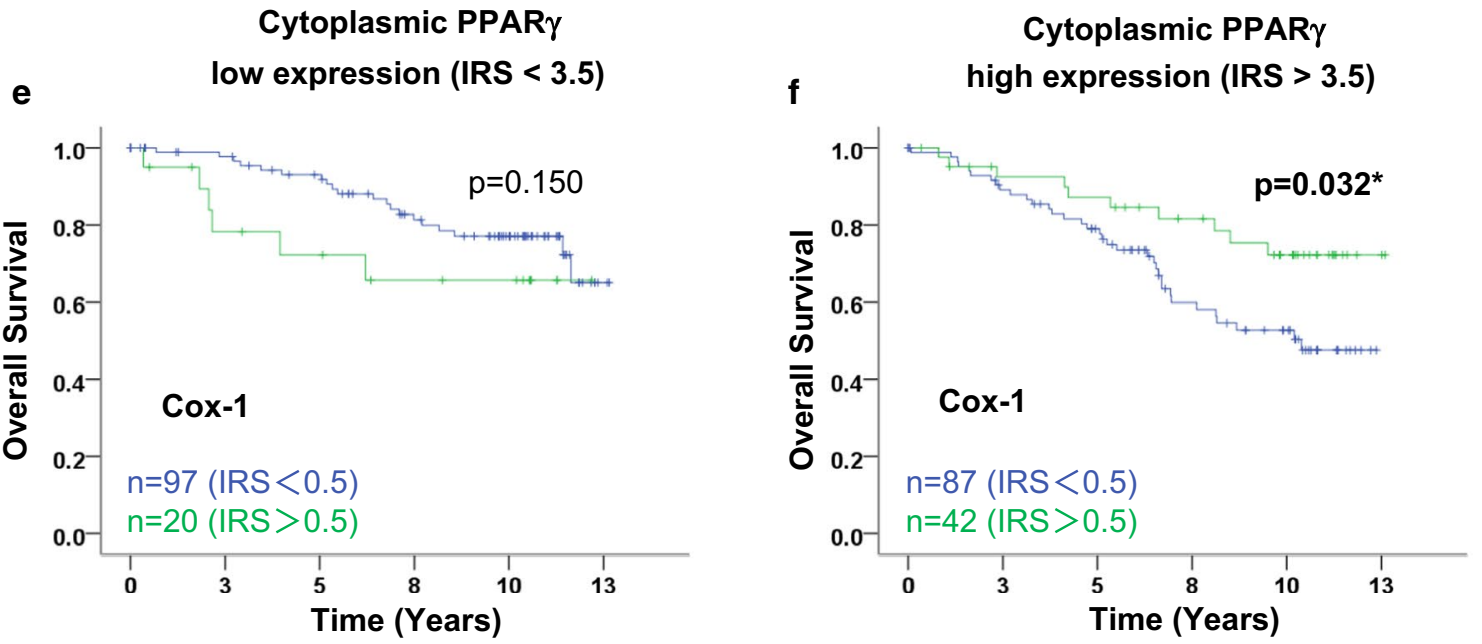

Fig. 3 Kaplan-Meier analysis of patient overall survival according to cytoplasmic PPARy and of Cox-1 expression in subgroups. Overall survival (OS) curves are presented according to cytoplasmic PPARy status in Cox-1 (a, b) and Cox-2 (c, d) subgroups. OS of Cox-1 is then presented according to cytoplasmic PPARY $(\mathbf{e}, \mathbf{f})$. The IRS cut-off values with the number of cases for each group are indicated in each graph. Statistical significance is shown as $p$-value from log-rank test $\left({ }^{*} p<0.05 ;{ }^{* *} p<0.01\right)$ 


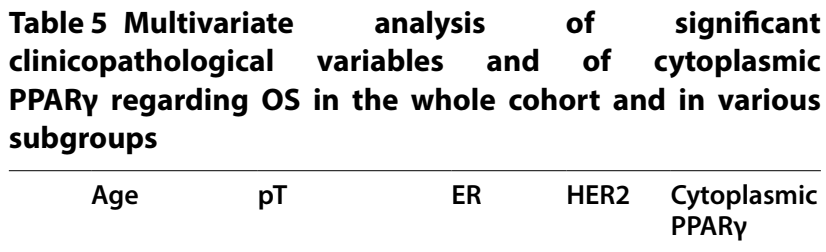

\begin{tabular}{|c|c|c|c|c|c|}
\hline \multicolumn{6}{|c|}{ Whole cohort } \\
\hline$p$ & $0.00001^{* * *}$ & $0.00000007^{* * *}$ & $0.008^{* *}$ & 0.154 & 0.129 \\
\hline $\mathrm{HR}$ & 1.040 & 3.769 & 0.508 & 1.616 & 1.457 \\
\hline \multicolumn{6}{|c|}{$\mathrm{N}$-cadherin low } \\
\hline $\mathrm{p}$ & $0.002^{* *}$ & $0.00037^{* * *}$ & $0.015^{*}$ & 0.528 & $0.044^{*}$ \\
\hline$H R$ & 1.041 & 3.370 & 0.420 & 1.341 & 1.996 \\
\hline \multicolumn{6}{|c|}{$\mathrm{N}$-cadherin high } \\
\hline$p$ & $0.000733^{* * *}$ & $0.000032^{* * *}$ & 0.174 & $0.035^{*}$ & 0.902 \\
\hline$H R$ & 1.045 & 6.121 & 0.583 & 3.437 & 1.052 \\
\hline \multicolumn{6}{|c|}{ Cox-1 negative } \\
\hline$p$ & $0.000023^{* * *}$ & $0.000008^{* * *}$ & 0.162 & 0.307 & $0.014^{*}$ \\
\hline$H R$ & 1.045 & 3.835 & 0.655 & 1.598 & 2.047 \\
\hline \multicolumn{6}{|c|}{ Cox-1 positive } \\
\hline$p$ & $0.017^{*}$ & $0.017^{*}$ & $0.023^{*}$ & 0.253 & 0.454 \\
\hline $\mathrm{HR}$ & 1.051 & 3.574 & 0.284 & 1.907 & 0.670 \\
\hline \multicolumn{6}{|c|}{ Cox-2 low } \\
\hline$p$ & $0.000002^{* * *}$ & $0.00008^{* * *}$ & $0.015^{*}$ & 0.969 & 0.102 \\
\hline$H R$ & 1.058 & 3.272 & 0.440 & 0.983 & 1.665 \\
\hline \multicolumn{6}{|c|}{ Cox-2 high } \\
\hline$p$ & 0.112 & $0.000343^{* *}$ & 0.801 & $0.021^{*}$ & 0.545 \\
\hline $\mathrm{HR}$ & 1.027 & 7.681 & 0.867 & 5.369 & 1.427 \\
\hline
\end{tabular}

$H R$, hazard ratio; $p$, $p$-value

In the sub-groups, the same cut-off as in Figs. 2 and 3 have been used, namely 3.5 for $\mathrm{N}$-Cadherin and 7 for Cox-2. Correlations are statistically significant for $\left.\mathrm{p}<0.05{ }^{*}\right)$ or $\mathrm{p}<0.01\left(^{* *}\right), \mathrm{p}<0.001$ (**) $^{* *}$

performed with nuclear or total PPAR $\gamma$, with Cox-1 or Cox-2, did not reveal any independent prognostic value as seen with cytoplasmic PPAR $\gamma$.

\section{Cox-1 expression is associated with favorable OS only in tumors with high cytoplasmic PPARy expression}

We then checked in the whole cohort that neither Cox-1 nor Cox-2 expression was related to OS (Additional file 1: Figure S2A, B respectively). In order to strengthen the link between PPARY, Cox1, and survival, we analyzed the prognostic value of Cox 1 according to PPAR $\gamma$ levels. By selecting patients with tumors expressing high levels of cytoplasmic PPARy (Fig. 3f), Cox-1 expression appeared statistically correlated to a better OS of patients $(\mathrm{p}=0.032)$. For patients with tumors expressing low levels of cytoplasmic PPARY (Fig. 3e), no correlation with OS appeared although we observed again an opposite trend, with Cox-1 expression numerically correlated with a poor OS. Altogether, these data strengthened our results demonstrating that the relative expression of cytoplasmic PPARY and Cox-1 is linked to prognosis in primary $\mathrm{BC}$, with a high cytoplasmic PPAR $/$ Cox-1 ratio being a marker for poor prognosis, and that Cox-1 expression correlated with longer OS in an unselected cohort.

\section{Discussion}

The aim of this study was to characterize the intracellular expression and possible interplay of PPAR $y$ and the Cox (Cox-1 and Cox-2) expression in a wide range of $\mathrm{BC}$ specimens, in relation with the clinicopathological parameters as well as patient survival. We already demonstrated that cytoplasmic PPAR $\gamma$ is overexpressed in BRCA1 mutated BC compared to sporadic cases, but without correlation to survival [27]. In previous surveys, either nuclear PPARy or cytoplasmic PPARy had a correlation with an improved clinical outcome of $\mathrm{BC}$ patients $[8,36,37]$, but fewer specific subgroups of patients were analyzed.

Our data demonstrated that PPARy expression was detected in a majority of $\mathrm{BC}$ tissues and that it is predominantly localized in cytoplasm $(92.3 \%$ vs $18.7 \%)$. This is in accordance with previous studies [8, 27, 38]. However, positive PPAR immunoreactivity was previously described as mainly nuclear in normal cells from benign samples; in malignant cells, a decreased expression was shown which was related to a favorable survival for patients [37, 39]. In addition, it was demonstrated that casein-kinase-II-dependent phosphorylation of PPAR $\gamma$ leads to subcellular translocation of PPAR $\gamma$ from cytoplasm to nucleus regulated by CRM1 and that urokinasetype plasminogen activator promoted atherogenesis in hepatocytes by downregulating PON1 gene expression via PPAR $\gamma$ nuclear export mechanism [9, 40]. Intracellular distribution of PPAR $\gamma$ was observed in $\mathrm{BC}$ tissues and cell lines [41], suggesting that poorly differentiated samples and highly invasive cell lines displayed mainly cytoplasmic PPAR $\gamma$ expression. Moreover, cytoplasmic localization of PPARY was described as being mediated by Skp2 upon MEK1-dependent mechanism indicating cytoplasmic translocation of PPARY promoted tumorigenesis in BC. In another study [17], $\alpha$-ESA, considered as a PPARy agonist like rosiglitazone, as well as GLA [38], suppressed cell growth in BC cell lines by activating PPAR $\gamma$ nuclear compartmentalization, which suggested that nuclear localization of PPAR $\gamma$ plays a role in anti-cancer functions in $\mathrm{BC}$. Besides the predominant cytoplasmic localization of PPAR $\gamma$, our data demonstrate a significant correlation between total and cytoplasmic PPAR $\gamma$ and an inverse relationship between cytoplasmic and nuclear PPARY (Table 3), supporting the hypothesis of the translocation mechanism of PPAR $\gamma$ in the carcinogenic process. 
Concerning the correlation between PPAR $\gamma$ expression and clinicopathological features or aggressiveness markers, our data demonstrated that nuclear PPAR $\gamma$ expression was inversely correlated with tumor grade, HER2 and $\mathrm{N}$-cadherin expression, whereas total and cytoplasmic PPAR $\gamma$ were positively related with HER2, CD133, and $\mathrm{N}$-cadherin (Fig. 1 and Table 4). These correlations strongly suggest that only cytoplasmic PPAR $\gamma$ was associated with the more aggressive tumors, namely ER negative, HER2 positive, CD133 (as a CSC marker [33, 34]) positive and NCAD (as an EMT marker [35]) positive sub-groups. Nonetheless, cytoplasmic PPAR $\gamma$ expression being much higher (15 fold) than nuclear one, total PPAR $y$ expression exhibited similar association as cytoplasmic one with tumor aggressiveness. Several authors also found, as we did, a negative correlation between nuclear PPAR $\gamma$ and histological grade [36, 37, 39], and one paper indicated that nuclear PPAR $\gamma$ was negatively associated with HER2 [39]. Interestingly, PPAR $\gamma$ protein was expressed in both transfected MCF-7/Neo and MCF-7/HER2, but with higher levels of expression in the MCF-7/HER2 cells [42]. Moreover, HER2 up-regulated PPAR $\gamma$ expression, causing $\mathrm{BC}$ cells to become resistant to PPAR $\gamma$ ligand response [43]. Both CD133 and N-cadherin play a critical role in cancer migratory and invasive properties. Indomethacin could decrease CD133 expression, which means reducing CSCs via inhibiting Cox-2 and NOTCH/HES1 and activating PPARY [44]. According to our previous work [29], N-cadherin-positive tumors without LNM had a significantly shorter survival time. Enhanced activity of PPAR $\gamma$ had an inhibition on TGF- $\beta$ induction of $\mathrm{N}$-cadherin promoter in lung carcinoma cell lines [45].

Overall, nuclear PPAR $\gamma$ possess a possible protective role against $\mathrm{BC}$ development, whereas cytoplasmic PPAR $\gamma$ was defined as a promoter during $\mathrm{BC}$ progression. Our data emphasize this hypothesis of opposite correlation of nuclear PPAR $\gamma$ with antioncogenic parameters and of cytoplasmic PPAR $\gamma$ with oncogenic or aggressive parameters. Survival analysis in the whole cohort demonstrated that only cytoplasmic PPAR $\gamma$ expression had a strong correlation with poor OS (Fig. 2), whereas both total and cytoplasmic PPARy expression had a strong correlation with poor RFS (Additional file 1: Figure S1). As described earlier, PPAR $\gamma$ activation has been shown to exert antiproliferative and pro-apoptotic effects in BC cell lines [16-18, 46]. Moreover, cell death has been shown to be triggered in $\mathrm{BC}$ cell lines through the localization of PPARY into the nucleus followed by the induction of Fas ligand [19]. The analysis of apoptosis markers will be necessary to give more insight in the molecular mechanisms underlying the differential effects of cytoplasmic and nuclear PPARy.
Analysis of Cox in our cohort of primary BC substantiated that both Cox-1 and Cox-2 were dominantly localized in cytoplasm with a predominant negative or low expression for Cox-1 and a high expression for Cox-2 (Table 2). However, they were both significantly and positively correlated with total and cytoplasmic PPAR $\gamma$, whereas only Cox- 2 expression was negatively correlated with nuclear PPARY (Table 3). Additionally, similarly to cytoplasmic PPAR $\gamma$, Cox-1 was positively associated with HER2, CD133, and N-cadherin. Nonetheless, it was inversely related to $\mathrm{LN}$ involvement (Table 4), suggesting the hypothesis that Cox-1 expression may be related to the evolution of the tumor, especially expressed during the early non-metastatic stages of BC. Moreover, Cox-2 was positively related to $\mathrm{Ki}-67, \mathrm{CD} 133$, and $\mathrm{N}$-cadherin. In breast CSCs deprived from tumor cells of HER2/Neu mice, both Cox-1 and Cox- 2 genes, belonging to a set of genes representing possible molecular targets correlated with BC survival, are overexpressed [47]. Compared to Cox-2, less attention was paid to Cox-1 in tumors and fewer data elucidated that Cox-1 selective inhibitors, such as SC-560 [48], catechin [49] and FR122047 [50], suppressed cell growth in BC. More interestingly, corticotropin-releasing factor, a hypothalamic neuropeptide, promoted cell invasiveness in MCF-7 BC cell line via induction of Cox-1 expression but not of Cox-2, as well as the production of prostaglandins [51].

Cox was officially known as an enzyme responsible for the synthesis of PGs from arachidonic acid. The role of Cox-2 and PPARy in pro-apoptosis and tumor regression was explored in lung cancer cell lines, demonstrating that cannabidiol induced the upregulation of Cox-2 and PPAR $\gamma$ following a nuclear translocation of PPAR by Cox-2 dependent PGs [52]. Modulation of $15 \mathrm{~d}-\mathrm{PGJ}{ }_{2}$, a natural ligand of PPAR $\gamma$, may influence the development of $B C$ progress [53]. Cox-1 could lead to the activation of PPARY [54]. Our finding of a strong correlation between Cox-1 and cytoplasmic PPARy highlight their possible interaction in BC cells. Furthermore, Cox-1 and Cox-2 expression has been shown to be strongly associated in BC to the expression of the aromatase (CYP19A1) [55] which has been shown to be associated with a poor survival of ER positive BC patients [56]. As a consequence, the link of cytoplasmic PPARY with poor survival might involve the dysregulation of CYP19A1 expression through Cox activity. Obviously, other mechanisms might participate and further work will be needed to decipher the precise underlying mechanisms.

In our study, although neither Cox-1 nor Cox- 2 were related to OS in the whole cohort (Additional file 1: Figure S2A, B), high cytoplasmic PPAR $\gamma$ expression was significantly associated with poor OS in the Cox-1 negative subgroup and in the Cox-2 low expression subgroup 
(Fig. 3a, c). In addition, we also observed that the trend was inverted with an apparent, although not significant, better prognosis for the patients with high cytoplasmic PPAR $y$ expression in the Cox-1 positive subgroup. Moreover, the data we generated demonstrate that cytoplasmic PPAR $\gamma$ expression is an independent prognostic marker in the Cox-1 negative subgroups, related to a twofold higher risk of death for those patients. Interestingly, positive Cox-1 expression (inversely related to the LN status) was defined as a favorable outcome marker for the patients with high cytoplasmic PPARy expression (Fig. 3f), and tended to be a bad outcome marker for the patients with low cytoplasmic PPARy expression. Our data suggest that the expression of Cox-1 and cytoplasmic PPAR $\gamma$ are interdependent, with the ability for Cox-1 to rescue the negative impact of cytoplasmic PPAR $\gamma$ on patient outcome. A hypothesis could be a potential role of Cox-1 in nucleocytoplasmic translocation of PPAR $\gamma$, thereby suppressing tumor growth.

\section{Conclusions}

In our primary $\mathrm{BC}$ cohort, PPAR $\gamma$ was predominantly expressed in cytoplasm of $\mathrm{BC}$ cells and may perform different roles in tumorigenesis according to its subcellular localization. Cytoplasmic PPAR $\gamma$ was strongly correlated with Cox-1 mainly, as well as with other bad prognosis markers (HER2, CD133, N-cadherin), contributing to explore their interactions during $\mathrm{BC}$ progression. High cytoplasmic PPAR $\gamma$ expression was correlated with short OS in the whole cohort and in several subgroups with good prognosis. A major conclusion is that this bad prognostic impact of cytoplasmic PPAR $\gamma$ depends on Cox-1 expression, as it is worse when Cox-1 is negative and lost when Cox-1 is expressed. Altogether, this leads to the strengthening that the intracellular PPARY localization might be involved in tumorigenesis, and to the conclusion that cytoplasmic PPAR $\gamma$ may be defined as a potential therapeutic target and a prognostic marker in BC. Further analyses are now needed to decipher the molecular mechanisms underlying PPAR $\gamma$ interplay with Cox-1 and Cox-2 to modulate $\mathrm{BC}$ aggressiveness through the control of cell proliferation and/or apoptosis.

\section{Supplementary information}

Supplementary information accompanies this paper at https://doi. org/10.1186/s12967-020-02271-6.

Additional file 1: Figure S1. Kaplan-Meier analysis in the whole cohort of patient overall survival according to Total PPARy expression and patient relapse-free survival according to total, cytoplasmic and nuclear PPARy expression. Overall survival (OS) curves are presented according to total PPARy (A) status. Relapse-free survival (RFS) curves are presented according to total (B), cytoplasmic (C) and nuclear (D) PPARy status. The IRS cut-off values with the number of cases for each group are indicated in each graph. Statistical significance is shown as $p$-value from log-rank test $\left({ }^{*}: p<0.05 ;{ }^{* *}: p<0.01\right)$. Figure $\mathbf{S 2}$. Kaplan-Meier analysis in the whole cohort of patient overall survival according to Cox-1 or Cox-2 expression. Overall survival (OS) curves are presented according to Cox-1 (A) or Cox-2 expression. The IRS cut-off values with the number of cases for each group are indicated in each graph. Statistical significance is shown as p-value from log-rank test $\left(^{*}: p<0.05 ;{ }^{* *}: p<0.01\right)$.

\section{Abbreviations}

BC: Breast cancer; Cox: Cyclooxygenase; CSC: Cancer stem cell; DCIS: Ductal carcinoma in situ; EMT: Epithelial mesenchymal transition; ER: Estrogen receptor; FISH: Fluorescence in situ hybridization; HER2: Human epidermal growth factor receptor 2; HR: Hazard ratio; IHC: Immunohistochemistry; IRS: Immunoreactive score; LCoR: Ligand-dependent corepressor; LMU: Ludwig Maximilians University; LNM: Lymph node metastasis; NR: Nuclear receptor; NST: Non-special type; OS: Overall survival; PBS: Phosphate buffered saline; PG: Prostaglandin; pN: Primary lymph node; PPARs: Peroxisome proliferator-activated receptors; PPARY: Peroxisome proliferator-activated receptor $\gamma$; PPREs: Proliferator-activated receptor response elements; PR: Progesterone receptor; PT: Primary tumor size; RAR: Retinoic acid receptor; RFS: Relapse-free survival; RIP140: Receptor interacting protein of 140 kDa; ROC-curve: Receiver operating characteristic curve; RXR: Retinoid X receptor; TNBC: Triple-negative breast cancer; TPA: Tetradecanoyl phorbol acetate.

\section{Acknowledgements}

Not applicable.

\section{Authors' contributions}

SS, VC and UJ conceived and supervised the project. DM, ND and SM provided the samples and the related clinical data. MK and VW performed the stainings with the help of CK and the supervision of UJ. WS performed most analysis and wrote the first draft of the paper. SS, VC, UJ and NH contributed to manuscript writing and editing. All authors read and approved the final manuscript.

Funding

SS salary was supported by the University Paul Sabatier in Toulouse (France). WS was supported by the China Scholarship Council (CSC) with a 3-year stipend (No. 201606170096) at the University of Munich. The project was supported by the "Centre de Coopération Universitaire Franco-Bavarois" (CCUFB) or "Bayerisch-Französishes Hochschilzentrum" (BFHZ), Project funding FK19-15.

\section{Availability of data and materials}

All data generated or analysed during this study are included in this published article and its Additional file.

\section{Ethics approval and consent to participate}

This study was approved by the Ethical Committee of the Medical Faculty, Ludwig-Maximilian-University, Munich, Germany (approval number 048-08) and informed consent was obtained from all patients.

\section{Consent for publication}

Not applicable.

\section{Competing interests}

The authors declare no competing interests.

\section{Author details}

${ }^{1}$ Breast Center, Department of Obstetrics and Gynecology, University Hospital, LMU Munich, Munich, Germany. ${ }^{2}$ Department of Pathology, LMU Munich, Munich, Germany. ${ }^{3}$ IRCM-Institut de Recherche en Cancérologie de Montpellier, INSERM U1 194, Université Montpellier, Parc Euromédecine, 208 rue des Apothicaires, 34298 Montpellier Cedex 5, France. ${ }^{4}$ Faculté des Sciences Pharmaceutiques, Université Paul Sabatier Toulouse III, 31062 Toulouse Cedex 09, France. ${ }^{5}$ Cholesterol Metabolism and Therapeutic Innovations, Cancer Research Center of Toulouse (CRCT), UMR 1037, CNRS, Inserm, UPS, Université de Toulouse, 31037 Toulouse, France.

Received: 30 August 2019 Accepted: 14 February 2020

Published online: 21 February 2020 


\section{References}

1. Bray F, Ferlay J, Soerjomataram I, Siegel RL, Torre LA, Jemal A. Global cancer statistics 2018: GLOBOCAN estimates of incidence and mortality worldwide for 36 cancers in 185 countries. CA Cancer J Clin. 2018:68(6):394-424

2. Harbeck N, Penault-Llorca F, Cortes J, Gnant M, Houssami N, Poortmans P, et al. Breast cancer. Nat Rev Dis Primers. 2019;5:66.

3. Kast K, Link T, Friedrich K, Petzold A, Niedostatek A, Schoffer O, et al. Impact of breast cancer subtypes and patterns of metastasis on outcome. Breast Cancer Res Treat. 2015;150:621-9.

4. Poorolajal J, Nafissi N, Akbari ME, Mahjub H, Esmailnasab N, Babaee E. Breast cancer survival analysis based on immunohistochemistry subtypes (ER/PR/HER2): a retrospective cohort study. Arch Iran Med. 2016;19:680-6.

5. Liu CY, Wu CY, Petrossian K, Huang TT, Tseng LM, Chen S. Treatment for the endocrine resistant breast cancer: current options and future perspectives. J Steroid Biochem Mol Biol. 2017;172:166-75.

6. Helsen C, Claessens F. Looking at nuclear receptors from a new angle. Mol Cell Endocrinol. 2014;382:97-106.

7. Kota BP, Huang TH, Roufogalis BD. An overview on biological mechanisms of PPARs. Pharmacol Res. 2005:51:85-94.

8. Papadaki I, Mylona E, Giannopoulou I, Markaki S, Keramopoulos A, Nakopoulou L. PPARgamma expression in breast cancer: clinical value and correlation with ERbeta. Histopathology. 2005;46:37-42.

9. von Knethen A, Tzieply N, Jennewein C, Brune B. Casein-kinase-IIdependent phosphorylation of PPARgamma provokes CRM1-mediated shuttling of PPARgamma from the nucleus to the cytosol. J Cell Sci. 2010;123:192-201.

10. Janani C, Ranjitha Kumari BD. PPAR gamma gene-a review. Diabetes Metab Syndr. 2015:9:46-50.

11. Elstner E, Williamson EA, Zang C, Fritz J, Heber D, Fenner M, et al. Novel therapeutic approach: ligands for PPARgamma and retinoid receptors induce apoptosis in bcl-2-positive human breast cancer cells. Breast Cancer Res Treat. 2002;74:155-65.

12. Fenner $\mathrm{MH}$, Elstner E. Peroxisome proliferator-activated receptor-gamma ligands for the treatment of breast cancer. Expert Opin Investig Drugs. 2005;14:557-68.

13. Patitucci C, Couchy G, Bagattin A, Caneque T, de Reynies A, Scoazec JY, et al. Hepatocyte nuclear factor 1alpha suppresses steatosis-associated liver cancer by inhibiting PPARgamma transcription. J Clin Invest. 2017:127:1873-88.

14. Ahn YH, Yang Y, Gibbons DL, Creighton CJ, Yang F, Wistuba II, et al. Map2k4 functions as a tumor suppressor in lung adenocarcinoma and inhibits tumor cell invasion by decreasing peroxisome proliferator-activated receptor gamma2 expression. Mol Cell Biol. 2011;31:4270-85.

15. Yang K, Fan KH, Lamprecht SA, Edelmann W, Kopelovich L, Kucherlapati $\mathrm{R}$, et al. Peroxisome proliferator-activated receptor gamma agonist troglitazone induces colon tumors in normal C57BL/6J mice and enhances colonic carcinogenesis in Apc1638 N/+ Mlh1+/- double mutant mice. Int J Cancer. 2005;116:495-9.

16. Bonofiglio D, Gabriele S, Aquila S, Qi H, Belmonte M, Catalano S, et al. Peroxisome proliferator-activated receptor gamma activates fas ligand gene promoter inducing apoptosis in human breast cancer cells. Breast Cancer Res Treat. 2009:113:423-34.

17. Moon HS, Guo DD, Lee HG, Choi YJ, Kang JS, Jo K, et al. Alpha-eleostearic acid suppresses proliferation of MCF-7 breast cancer cells via activation of PPARgamma and inhibition of ERK 1/2. Cancer Sci. 2010;101:396-402.

18. Catalano S, Mauro L, Bonofiglio D, Pellegrino M, Qi H, Rizza P, et al. In vivo and in vitro evidence that PPARgamma ligands are antagonists of leptin signaling in breast cancer. Am J Pathol. 2011;179:1030-40

19. Chen L, Yuan Y, Kar S, Kanchi MM, Arora S, Kim JE, et al. PPARgamma ligand-induced annexin A1 expression determines chemotherapy response via deubiquitination of death domain kinase RIP in triple-negative breast cancers. Mol Cancer Ther. 2017;16:2528-42.

20. Subbaramaiah K, Dannenberg AJ. Cyclooxygenase-2 transcription is regulated by human papillomavirus $16 \mathrm{E} 6$ and $\mathrm{E7}$ oncoproteins: evidence of a corepressor/coactivator exchange. Cancer Res. 2007:67:3976-85.

21. Cornett AL, Lutz CS. Regulation of COX-2 expression by miR-146a in lung cancer cells. RNA. 2014;20:1419-30.

22. Hashemi Goradel N, Najafi M, Salehi E, Farhood B, Mortezaee K. Cyclooxygenase-2 in cancer: a review. J Cell Physiol. 2019;234:5683-99.
23. Kino Y, Kojima F, Kiguchi K, Igarashi R, Ishizuka B, Kawai S. Prostaglandin E2 production in ovarian cancer cell lines is regulated by cyclooxygenase-1, not cyclooxygenase-2. Prostaglandins Leukot Essent Fatty Acids. 2005;73:103-11.

24. Hwang D, Scollard D, Byrne J, Levine E. Expression of cyclooxygenase-1 and cyclooxygenase-2 in human breast cancer. J Natl Cancer Inst. 1998:90:455-60.

25. Fahlen M, Zhang H, Lofgren L, Masironi B, von Schoultz E, von Schoultz B, et al. Expression of cyclooxygenase-1 and cyclooxygenase-2, syndecan-1 and connective tissue growth factor in benign and malignant breast tissue from premenopausal women. Gynecol Endocrinol. 2017;33:353-8.

26. Elston EW, Ellis IO. Method for grading breast cancer. J Clin Pathol. 1993;46:189-90.

27. Heublein S, Mayr D, Meindl A, Kircher A, Jeschke U, Ditsch N. Vitamin $D$ receptor, Retinoid $X$ receptor and peroxisome proliferator-activated receptor gamma are overexpressed in BRCA1 mutated breast cancer and predict prognosis. J Exp Clin Cancer Res. 2017;36:57.

28. Harbeck N, Gnant M. Breast cancer. Lancet. 2017:389:1134-50.

29. Bock C, Kuhn C, Ditsch N, Krebold R, Heublein S, Mayr D, et al. Strong correlation between N-cadherin and CD133 in breast cancer: role of both markers in metastatic events. J Cancer Res Clin Oncol. 2014;140:1873-81.

30. Weissenbacher T, Hirte E, Kuhn C, Janni W, Mayr D, Karsten U, et al. Multicentric and multifocal versus unifocal breast cancer: differences in the expression of E-cadherin suggest differences in tumor biology. BMC Cancer. 2013:13:361.

31. Sixou S, Muller K, Jalaguier S, Kuhn C, Harbeck N, Mayr D, et al. Importance of RIP140 and LCoR sub-cellular localization for their association with breast cancer aggressiveness and patient survival. Transl Oncol. 2018:11:1090-6.

32. Jeschke U, Zhang X, Kuhn C, Jalaguier S, Colinge J, Pfender K, et al. The prognostic impact of the aryl hydrocarbon receptor (AhR) in primary breast cancer depends on the lymph node status. Int J Mol Sci. 2019:20:1016

33. Yang F, Xu J, Tang L, Guan X. Breast cancer stem cell: the roles and therapeutic implications. Cell Mol Life Sci. 2017;74:951-66.

34. Brugnoli F, Grassilli S, Al-Qassab Y, Capitani S, Bertagnolo V. CD133 in breast cancer cells: more than a stem cell marker. J Oncol. 2019:2019:7512632

35. Ashaie MA, Chowdhury EH. Cadherins: the superfamily critically involved in breast cancer. Curr Pharm Des. 2016:22:616-38.

36. Suzuki T, Hayashi S, Miki Y, Nakamura Y, Moriya T, Sugawara A, et al. Peroxisome proliferator-activated receptor gamma in human breast carcinoma: a modulator of estrogenic actions. Endocr Relat Cancer. 2006;13:233-50.

37. Jiang Y, Zou L, Zhang C, He S, Cheng C, Xu J, et al. PPARgamma and Wnt/ beta-Catenin pathway in human breast cancer: expression pattern, molecular interaction and clinical/prognostic correlations. J Cancer Res Clin Oncol. 2009;135:1551-9.

38. Jiang WG, Redfern A, Bryce RP, Mansel RE. Peroxisome proliferator activated receptor-gamma (PPAR-gamma) mediates the action of gamma linolenic acid in breast cancer cells. Prostaglandins Leukot Essent Fatty Acids. 2000;62:119-27.

39. Abduljabbar R, Al-Kaabi MM, Negm OH, Jerjees D, Muftah AA, Mukherjee $A$, et al. Prognostic and biological significance of peroxisome proliferatoractivated receptor-gamma in luminal breast cancer. Breast Cancer Res Treat. 2015;150:511-22.

40. Khateeb J, Kiyan Y, Aviram M, Tkachuk S, Dumler I, Fuhrman B. Urokinasetype plasminogen activator downregulates paraoxonase 1 expression in hepatocytes by stimulating peroxisome proliferator-activated receptorgamma nuclear export. Arterioscler Thromb Vasc Biol. 2012;32:449-58.

41. Cheng H, Meng J, Wang G, Meng Y, Li Y, Wei D, et al. Skp2 regulates subcellular localization of PPARgamma by MEK signaling pathways in human breast cancer. Int J Mol Sci. 2013:14:16554-69.

42. Konopleva M, Zhang W, Shi YX, McQueen T, Tsao T, Abdelrahim M, et al. Synthetic triterpenoid 2-cyano-3,12-dioxooleana-1,9-dien-28-oic acid induces growth arrest in HER2-overexpressing breast cancer cells. Mol Cancer Ther. 2006:5:317-28.

43. Yang Z, Bagheri-Yarmand R, Balasenthil S, Hortobagyi G, Sahin AA, Barnes CJ, et al. HER2 regulation of peroxisome proliferator-activated receptor gamma (PPARgamma) expression and sensitivity of breast cancer cells to PPARgamma ligand therapy. Clin Cancer Res. 2003;9:3198-203. 
44. Moon CM, Kwon JH, Kim JS, Oh SH, Jin Lee K, Park JJ, et al. Nonsteroidal anti-inflammatory drugs suppress cancer stem cells via inhibiting PTGS2 (cyclooxygenase 2) and NOTCH/HES1 and activating PPARG in colorectal cancer. Int J Cancer. 2014;134:519-29.

45. Reka AK, Kurapati H, Narala VR, Bommer G, Chen J, Standiford TJ, et al. Peroxisome proliferator-activated receptor-gamma activation inhibits tumor metastasis by antagonizing Smad3-mediated epithelial-mesenchymal transition. Mol Cancer Ther. 2010;9:3221-32.

46. Nava-Villalba M, Nunez-Anita RE, Bontempo A, Aceves C. Activation of peroxisome proliferator-activated receptor gamma is crucial for antitumoral effects of 6-iodolactone. Mol Cancer. 2015;14:168.

47. Kanojia D, Zhou W, Zhang J, Jie C, Lo PK, Wang Q, et al. Proteomic profiling of cancer stem cells derived from primary tumors of HER2/Neu transgenic mice. Proteomics. 2012;12:3407-15.

48. Kundu N, Fulton AM. Selective cyclooxygenase (COX)-1 or COX-2 inhibitors control metastatic disease in a murine model of breast cancer. Cancer Res. 2002;62:2343-6.

49. McFadden DW, Riggs DR, Jackson BJ, Cunningham C. Additive effects of Cox-1 and Cox-2 inhibition on breast cancer in vitro. Int J Oncol. 2006;29:1019-23.

50. Jeong HS, Kim JH, Choi HY, Lee ER, Cho SG. Induction of cell growth arrest and apoptotic cell death in human breast cancer MCF-7 cells by the COX-1 inhibitor FR122047. Oncol Rep. 2010;24:351-6.

51. Androulidaki A, Dermitzaki E, Venihaki M, Karagianni E, Rassouli O, Andreakou $\mathrm{E}$, et al. Corticotropin releasing factor promotes breast cancer cell motility and invasiveness. Mol Cancer. 2009;8:30.
52. Ramer R, Heinemann K, Merkord J, Rohde H, Salamon A, Linnebacher M et al. COX-2 and PPAR-gamma confer cannabidiol-induced apoptosis of human lung cancer cells. Mol Cancer Ther. 2013;12:69-82.

53. Badawi AF, Badr MZ. Expression of cyclooxygenase-2 and peroxisome proliferator-activated receptor-gamma and levels of prostaglandin E2 and 15-deoxy-delta12,14-prostaglandin $\mathrm{J} 2$ in human breast cancer and metastasis. Int J Cancer. 2003;103:84-90.

54. Bauman DR, Rudnick SI, Szewczuk LM, Jin Y, Gopishetty S, Penning TM. Development of nonsteroidal anti-inflammatory drug analogs and steroid carboxylates selective for human aldo-keto reductase isoforms: potential antineoplastic agents that work independently of cyclooxygenase isozymes. Mol Pharmacol. 2005;67:60-8.

55. Brueggemeier RW, Richards JA, Petrel TA. Aromatase and cyclooxygenases: enzymes in breast cancer. J Steroid Biochem Mol Biol. 2003;86:501-7.

56. Friesenhengst A, Pribitzer-Winner T, Miedl H, Prostling K, Schreiber M. Elevated aromatase (CYP19A1) expression is associated with a poor survival of patients with estrogen receptor positive breast cancer. Horm Cancer. 2018;9:128-38.

\section{Publisher's Note}

Springer Nature remains neutral with regard to jurisdictional claims in published maps and institutional affiliations.
Ready to submit your research? Choose BMC and benefit from:

- fast, convenient online submission

- thorough peer review by experienced researchers in your field

- rapid publication on acceptance

- support for research data, including large and complex data types

- gold Open Access which fosters wider collaboration and increased citations

- maximum visibility for your research: over 100M website views per year

At BMC, research is always in progress.

Learn more biomedcentral.com/submissions 